
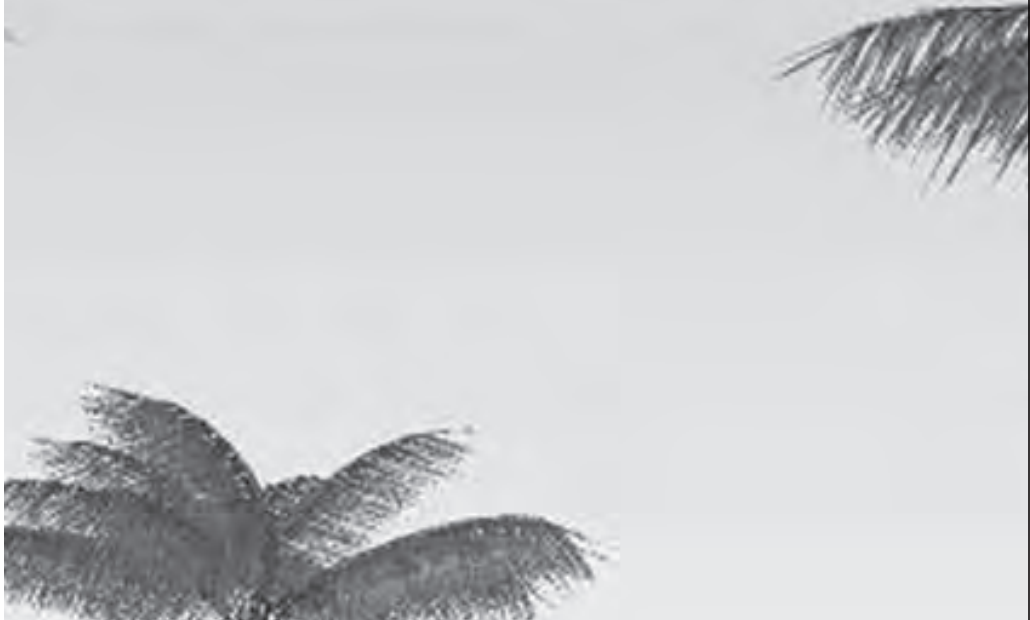

1. Doutorando em Geografia pelo Instituto de Geociências da Universidade Federal de Minas Gerais, mestre em Arquitetura e Urbanismo pelo Núcleo de Pós-graduação em Arquitetura e Urbanismo da Universidade Federal de Minas Gerais em 2007, arquiteto urbanista, graduado pela Pontifícia Universidade Católica de Minas Gerais em 2002.

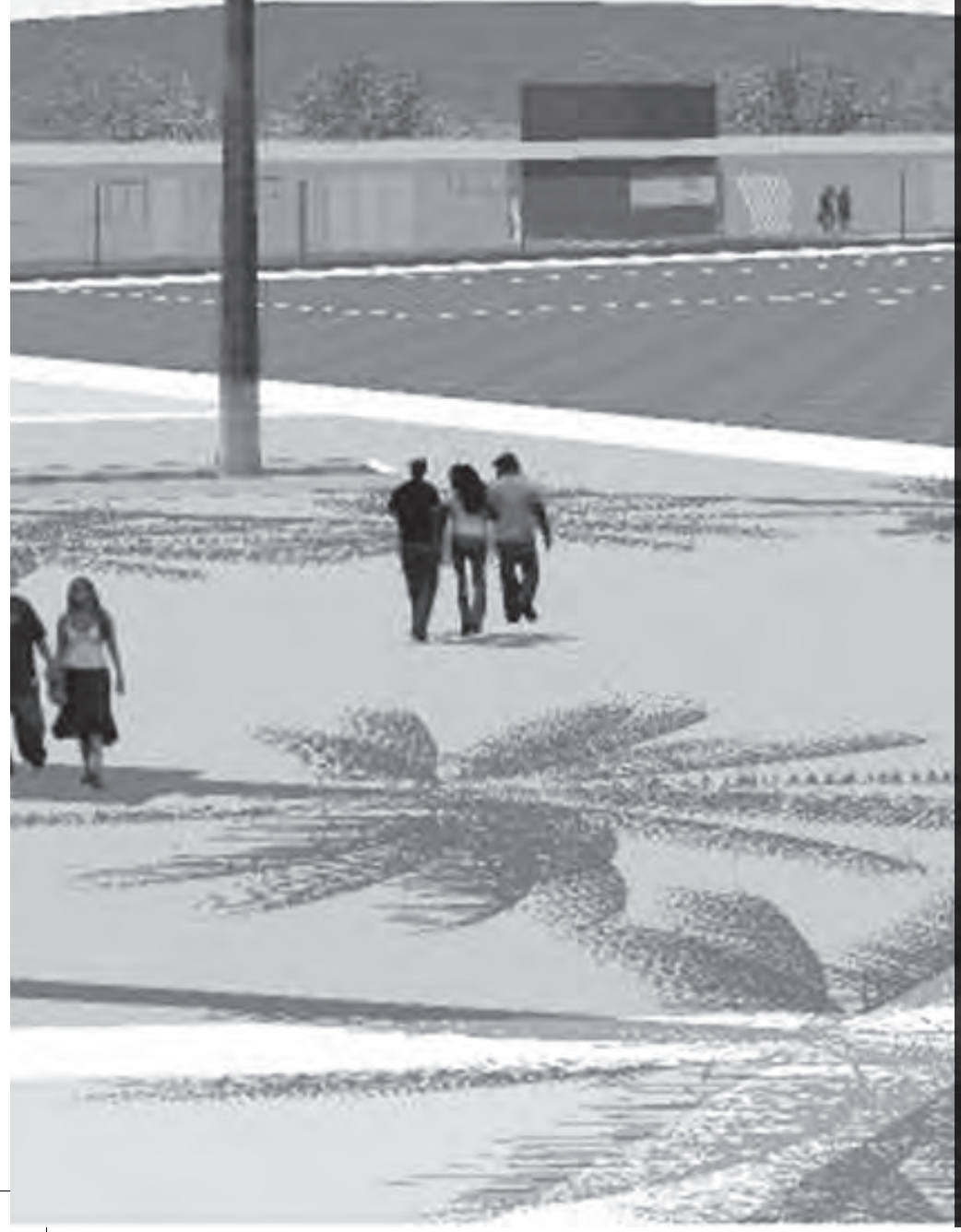




\title{
DINÂMICAS SOCIOESPACIAIS INTRAMETROPOLITANAS NO CONTEXTO DA RMBH: UMA ABORDAGEM DA ESCALA LOCAL ARTICULADA A PROCESSOS REGIONAIS NA OPERACÃO URBANA CONSORCIADA DO CÓRREGO SANTO ANTÔNIO, BETIM-MG
}

\author{
INTRA METROPOLITAN SOCIO-SPATIAL DYNAMICS IN THE CONTEXT OF \\ METROPOLITAN REGION OF BELO HORIZONTE: A STUDY ABOUTTHE \\ LOCAL SCALE ARTICULATED TO REGIONAL PROCESSES INTHE \\ CONSORTIAL URBAN OPERATION OF CÓRREGO SANTO ANTONNIO, \\ BETIM CITY, MINAS GERAIS STATE
}

Leandro de Aguiar e Souza ${ }^{1}$

\begin{abstract}
Resumo
Este trabalho apresenta uma contribuição ao debate acerca dos processos regionais e metropolitanos, baseada na importância da articulação entre diferentes escalas, do local ao regional. Dentre os conflitos e contradições identificados em abordagens sobre os espaços metropolitanos no Brasil, ressaltando-se, nesse bojo, as ações de planejamento e gestão urbana, destaca-se a dificuldade de compatibilização entre as propostas feitas na escala regional e os impactos identificados na escala local. Nesse sentido, foi analisado o caso da Operação Urbana Consorciada do Córrego Santo Antônio, localizada no Município de Betim, Vetor Oeste da Região Metropolitana de Belo Horizonte, que teve como objetivo realizar um conjunto de ações baseadas nas aqui denominadas dinâmicas socioespaciais intrametropolitanas.
\end{abstract}

Palavras-chave: planejamento urbano e ambiental; dinâmicas socioespaciais; processos metropolitanos.

\begin{abstract}
The present work presents a discussion about the metropolitan and regional processes, based on the importance of coordination between different scales, from local to regional. Among the conflicts and contradictions identified in studies about the metropolitan areas in Brazil, we highlight the difficulty of reconciling the proposals made at the regional scale and identified impacts in the local scale. In this sense was analysed the case of the Consortial Urban Operation of Córrego Santo Antônio, located in the Municipality of Betim, Minas Gerais, Brazil, aiming to implement a set of actions based on the intra-metropolitan socio spatial dynamics.
\end{abstract}

Keywords: environmental and urban planning; socio-spatial dynamics; metropolitan processes. 


\section{Notas introdutórias sobre a compreensão do espaço metropolitano}

O espaço metropolitano é aqui entendido como o espaço urbano policêntrico, caracterizado por uma centralidade de primeiro nível que predomina sobre as demais, por meio da polarização de fluxos de naturezas diversas.

Essa espacialidade se aproxima do conceito de zona crítica discutida por Lefebvre (1999), em contraposição à noção de cidade, também discutida pelo autor. A zona crítica, constituída pela urbanização total do espaço, tendo em vista sua natureza ainda virtual, tem diversas características percebidas no processo de metropolização do espaço. Entre essas características, destaca-se o processo conhecido como implosão-explosão da cidade, do qual surge a ideia de urbanização extensiva, proposta por Monte-Mor (1994, p. 2), que consiste na transformação da cidade em um núcleo urbano central, resultante da implosão do locus do poder, e o tecido urbano, definido como o conjunto de relações socioespaciais estendida à região resultante da explosão da cidade preexistente.

Sobre essa questão, Lefebvre (1999) ressalta que a extensão do tecido urbano não se resume às estruturas físicas da cidade, mas compreende também o conjunto de manifestações tipicamente urbanas que consome os resíduos da vida agrária. Sob essa perspectiva, um supermercado em pleno campo e um sistema rodoviário, articulados a um determinado centro urbano, compõe o tecido urbano (Lefebvre, 1999).

Monte-Mór (1994) ressalta que o processo de metropolização é a expressão mais concreta da zona crítica, do urbano de que fala Lefebvre. Nessa espacialidade metropolitana, que é sobretudo um processo, a antiga cidade industrial, implodida sobre o centro metropolitano e alguns de seus subcentros, recriou a concentração nodal do poder e seu tecido extensivo, explodido e equipado para a produção e para a reprodução coletiva, através da conformação de distritos industriais, indústrias isoladas, comércios e serviços em escalas diversas, bairros residenciais, cinturões agrícolas, áreas de lazer, entre outros (Monte-Mór, 1994).

Esse estágio seria o momento seguinte à chamada cidade industrial, que seria ampliada e complexificada pela inserção de novos processos.

O conceito de desenvolvimento geográfico desigual (uneven geographical development) proposto por Harvey (2006) também tem elementos aplicáveis ao processo de metropolização dos principais centros urbanos brasileiros. Harvey (2006, p. 415) destaca que o chamado desenvolvimento geográfico desigual é inerente ao processo de acumulação capitalista, que não se desenvolve sob uma superfície plana horizontal dotada de fontes homogêneas de matérias-primas, disponibilidade de mão de obra e um sistema de transportes bem estruturado em todas as direções. Diferentemente disso, tais processos se dão em ambientes significativamente distintos e com grandes descompassos em termos de atributos naturais e produtividade. Harvey (2006) ressalta ainda que as diferentes formas de mobilidade interagem no contexto da acumulação e, desse modo, constroem e fragmentam configurações espaciais na distribuição de forças 
produtivas, gerando diferenciações similares nas relações sociais e arranjos institucionais.

Desse modo, Reolon \& Souza (2006) ressaltam a temporalidade recente do processo de metropolização no Brasil, calcado na implantação de políticas públicas que tiveram como objetivo a industrialização de determinados centros urbanos, coincidentes, de um modo geral, com as capitais estaduais e seus municípios circundantes.

Como esse processo se deu de forma concentrada, os níveis de urbanização se deram de maneira desigual e culminaram no desenvolvimento de manchas de adensamento em lugares específicos do território.

Nesse contexto, Villaça (1998) ressalta a importância da localização urbana, que incrementa o valor de determinadas zonas ou regiões de uma dada aglomeração urbana ou metropolitana. $O$ autor ressalta que a disputa por essa localização privilegiada, por esse incremento de valor é um elemento fundamental da rede urbana brasileira, configurada de modo desigual.

Apesar de diversas discussões sobre o metropolitano trazerem consigo o entendimento da implosão-explosão da cidade, entende-se que tais abordagens priorizam os aspectos vinculados à concentração identificada nos centros urbanos analisados.

Sob esse aspecto, Catalão (2011) ressalta a importância da análise da dispersão urbana como categoria fundamental, uma vez que a cidade, segundo o autor, é tradicionalmente reconhecida como o lócus da concentração. A percepção dessa dialética concentração-dispersão é fundamental para o estabelecimento de uma discussão acerca do intrametropolitano analisado neste trabalho.

Ressalta-se que a compreensão do processo de produção do espaço metropolitano brasileiro não pode ocorrer sem uma análise do conflito vinculado às instâncias administrativas públicas. Esse conflito deve-se principalmente ao fato de a dinâmica socioespacial metropolitana ultrapassar, em diversos aspectos, a noção de município, base territorial da organização do Estado brasileiro, sobretudo após a Constituição Federal de 1988.

\section{A configuração normativa do espaço metropolitano brasileiro}

Para uma adequada discussão das dinâmicas socioespaciais intrametropolitanas apresentadas neste trabalho, é importante apresentar os fundamentos normativos que nortearam a formação institucional das regiões metropolitanas brasileiras a partir da década de 1970.

Em primeiro lugar, ressalta-se que a expressão região metropolitana surge normativamente no Brasil no parágrafo 10 do artigo 157 da Constituição Federal de 1967, quando é definido que:

A União, mediante lei complementar, poderá estabelecer regiões metropolitanas, constituídas por Municípios que, independentemente de sua vinculação administrativa, integrem a mesma comunidade socioeconômica, visando à realização de serviços de interesse comum. 
Essa normatização foi o reflexo de um processo intensificado duas décadas antes, baseado na concentração territorial das unidades de produção, na grande atração de mão de obra pouco qualificada e na participação expressiva do Poder Público na dotação de infraestruturas de apoio à produção (Marques, 2011). Essa situação resulta num conhecido e amplo processo de periferização e na concentração da população urbana em algumas regiões, que passam a constituir-se legalmente, a partir da Lei Complementar n¹4/1973, nas oito primeiras regiões metropolitanas do País (São Paulo, Belo Horizonte, Porto Alegre, Recife, Salvador, Curitiba, Belém e Fortaleza). A constituição dessas primeiras regiões metropolitanas, que, a partir de 1974, passa a incluir também a Região Metropolitana do Rio de Janeiro (por meio da Lei Complementar $n^{\circ}$ 20/1974), foi uma tentativa de gerir os conflitos que predominavam nesses espaços urbanos, prejudicando a eficiência do próprio processo produtivo (Marques, 2011).

Mares Guia (2001, p. 409) apresenta uma espécie de estado da arte desse processo, aplicado principalmente ao contexto da $\mathrm{RMBH}$, e demonstra que, a partir de 1975, com a criação da Comissão Nacional de Política Urbana e Regiões Metropolitanas (CNPU) e do Fundo Nacional de Desenvolvimento Urbano (FNDU), "Os órgãos metropolitanos passam a ser utilizados como repassadores de recursos do governo federal para os municípios situados nessas áreas e para os órgãos setoriais da esfera estadual que nelas atuavam".

No bojo desse fortalecimento técnico, econômico e político dos órgãos de gestão metropolitana, foi instituído, em 1974, o Plambel (Planejamento da Região Metropolitana de Belo Horizonte), que desempenhou um papel central na elaboração de estudos, planos e projetos vinculados aos processos metropolitanos.

Esse contexto, posteriormente revisto nos anos subsequentes, garantiu aos órgãos de gestão metropolitana brasileiros uma força técnica, política e, obviamente, financeira, que colocou, durante um determinado período, tais instituições no primeiro plano do planejamento e da gestão territorial. Esse modelo de repasse de recursos, progressivamente abandonado a partir do final da década de 1970, enfraqueceu-se até culminar com o modelo de descentralização administrativa contemplado na Constituição Federal de 1988 (Mares Guia, 2001). Esse enfraquecimento atingiu o Estado de Minas Gerais, culminando com a extinção do Plambel em 1996.

Ainda no âmbito dos desdobramentos pós-1988, Costa e Costa (2002) destacam, no modo como a questão metropolitana é tratada a partir de então, a ambiguidade quanto à própria concepção de gestão metropolitana, tendo em vista a responsabilidade dada ao Estado no estabelecimento de parâmetros para a gestão supramunicipal. Tal movimento tem como marca principal a transferência, da União para os Estados, do ônus político de discutir uma matéria que significa, de alguma forma, uma interferência na autonomia municipal recém-conquistada. Os autores ressaltam, por outro lado, que, no contexto de Minas Gerais, essa questão foi flexibilizada conforme a institucionalização de regiões metropolitanas foi condicionada "à adesão voluntária 
dos municípios, formalizada através dos legislativos municipais", contida na Constituição do Estado de Minas Gerais, promulgada em 1989 (COSTA e COSTA, 2002, p. 67).

Identificam-se, a partir de meados dos anos 2000, algumas tentativas de retomada das instâncias de gestão metropolitana no Brasil. No contexto da RMBH, destaca-se a criação da Agência de Desenvolvimento da Região Metropolitana de Belo Horizonte, em 2009, que se desdobra na elaboração do Plano Diretor de Desenvolvimento Integrado da RMBH, entre 2009 e 2010. Os resultados dessa retomada ainda são incipientes, e as dificuldades mostram-se contundentes, calcadas principalmente no modelo municipalista de ordenamento territorial adotado atualmente no País.

\section{Principais contradições identificadas}

Como pode ser verificado, o processo de produção do espaço metropolitano e sua consequente normalização trazem consigo uma série de contradições. Enquanto as dinâmicas socioespaciais metropolitanas são, em sua gênese, vinculadas a processos supramunicipais e regionais, o Município se consolida como a instância administrativa principal para as questões concernentes ao planejamento e à gestão dos espaços urbanos brasileiros.

Essa consolidação é reafirmada no Estatuto da Cidade (Lei $\left.n^{\circ} 10.257 / 2001\right)$, que, apesar de fazer referências isoladas às regiões metropolitanas, determina, com base nos artigos 182 e 183 da Constituição Federal de 1988, que o ordenamento territorial deve ter por base a instância administrativa municipal.

Essa lacuna normativa poderia ser minimizada pelo Projeto de Lei Federal $n^{\circ} 3.460 / 2004$, popularmente chamado de Estatuto das Metrópoles. Sobre esse projeto ainda pairam dúvidas se ele, apesar de conter avanços, tais como o estabelecimento de critérios para a criação de unidades regionais urbanas, será suficiente para romper a força preponderante do Município nas matérias ligadas ao ordenamento territorial urbano. Essa dificuldade é sentida no próprio processo de aprovação do projeto de lei, que aguarda atualmente a designação de relator para proferir parecer sobre o seu conteúdo (Câmara Federal, 2012).

Essas questões geram, na produção do espaço metropolitano brasileiro, uma espécie de conflito calcado na existência de processos regionais associados ao estabelecimento de instrumentos urbanísticos municipais. São verificados, nesse tipo de conflito, dois focos de tensão localizados em sentidos distintos. Se o primeiro, mais discutido, refere-se à complexidade dos processos, que demandariam instâncias e instrumentos de planejamento e gestão mais amplos que os limites municipais, na outra ponta, há uma demanda por outros modos de planejamento, de modo que não sejam simplesmente estabelecidas novas instâncias normativas, complexas e de difícil aplicação, cada vez mais distantes da escala local. E é esse um dos pontos fundamentais deste trabalho, que consiste no reconhecimento da complexidade de processos metropolitanos e regionais de modo que contemple, simultaneamente, os aspectos locais do lugar que interage com o referido processo. 
Outra questão comumente identificada nos processos metropolitanos brasileiros refere-se à competição entre municípios de uma dada região em detrimento da consolidação de processos cooperativos intermunicipais. A atração de novos empreendimentos representa possibilidades de aumento de postos de trabalho e de fontes de arrecadação, provenientes principalmente dos Impostos sobre Serviços, municipais, e das transferências estaduais atreladas ao fato gerador dos Impostos sobre a Circulação de Mercadorias e Serviços, de natureza estadual. Tais processos se constituem em uma espécie de capital eleitoral para determinados grupos de poder, e os impactos decorrentes da implantação de empreendimentos em um dado Município, sobretudo aqueles de natureza regional, externos aos municípios nos quais os empreendimentos são instalados, não têm sido efetivamente considerados.

Um desdobramento dessa questão está ligado ao sistema de arrecadação e distribuição de recursos aos municípios. Rolnik (2009) demonstra que a maior parte das fontes de recursos dos municípios está vinculada às transferências de outros níveis de governo, como pode ser verificado no quadro a seguir, extraído de Bremaeker (2008) e também citado pela autora.

\section{Quadro 1}

Receitas municipais por municípios, agrupados pelo número total de habitantes. Fonte: Bremacker (2008)

\begin{tabular}{l|c|c|c|c|c}
\hline \multirow{2}{*}{$\begin{array}{c}\text { Tipos de } \\
\text { municípios }\end{array}$} & \multicolumn{2}{|c|}{$\begin{array}{c}\text { Número total de municípios } \\
\text { por grupos }\end{array}$} & $\begin{array}{c}\text { Receitas de } \\
\text { transferências }\end{array}$ & $\begin{array}{c}\text { Receitas } \\
\text { fiscais }\end{array}$ & $\begin{array}{c}\text { Outras } \\
\text { receitas }\end{array}$ \\
\cline { 2 - 6 } & Número & $(\%)$ & $(\%)$ & $(\%)$ & $(\%)$ \\
\hline Total Brasil & 5.564 & $100,00 \%$ & & & \\
\hline Até 5.000 hab. & 1.267 & $22,77 \%$ & $91,10 \%$ & $2,49 \%$ & $6,42 \%$ \\
\hline $\begin{array}{l}\text { De 5.001 a } \\
10.000 \text { hab. }\end{array}$ & 1290 & $23,18 \%$ & $88,88 \%$ & $4,31 \%$ & $6,81 \%$ \\
\hline $\begin{array}{l}\text { De 10.001 } \\
\text { a 20.000 hab. }\end{array}$ & 1385 & $24,89 \%$ & $87,78 \%$ & $5,18 \%$ & $7,04 \%$ \\
\hline $\begin{array}{l}\text { De 20.001 } \\
\text { a 50.000 hab. }\end{array}$ & 1037 & $18,64 \%$ & $81,43 \%$ & $7,86 \%$ & $10,71 \%$ \\
\hline $\begin{array}{l}\text { De 50.001 } 100.000 \text { hab. } \\
\text { a 100 }\end{array}$ & 319 & $5,73 \%$ & $73,54 \%$ & $11,34 \%$ & $15,12 \%$ \\
\hline $\begin{array}{l}\text { De 100.001 } \\
\text { a 500.000 hab. }\end{array}$ & 229 & $4,12 \%$ & $60,20 \%$ & $19,77 \%$ & $20,03 \%$ \\
\hline Mais de 500.000 \\
hab.
\end{tabular}

Como pode ser verificado no quadro acima, apenas o grupo dos 37 municípios com mais de 500 mil habitantes tem um montante de receitas de transferências inferior à quantia referente às receitas fiscais próprias somadas a outras fontes de receitas. Os demais municípios que, somados, chegam a 99,34\% do número total de municípios brasileiros, apresentam, conforme o estudo de Bremaeker (2008), um orçamento cuja receita preponderante provém de outras instâncias de governo. Ressalta-se que o quadro apresentado pelo autor e discutido por Rolnik (2009) não diferencia os repasses provenientes dos governos federais e estaduais, e isso 
impossibilita uma análise quanto aos valores ligados ao repasse proveniente do ICMS que, de alguma forma, tem relação com o volume de mercadorias produzido em um determinado município. De qualquer modo, a análise de Rolnik (2009) demonstra como um grande número de municípios encontra-se em uma situação frágil com relação à sua autonomia financeira para planejar e gerir seu território, bem como para realizar novos investimentos nesse sentido.

Essa discussão, no entanto, merece ser significativamente ampliada, por meio da realização de estudos que demonstrem as demandas de um determinado Município inserido em algum processo regional específico, os impactos desses processos (internalidades e externalidades), a produção de receitas vinculadas ao que realmente foi produzido no próprio Município, o que de fato é proveniente de transferências efetivas e quais são os custos provenientes de processos externos.

\section{Justificativas para uma discussão baseada na escala intrametropolitana}

Villaça (1998), ao conceituar o termo intraurbano, reconhece que este poderia ser redundante, tendo em vista que, sendo o intraurbano um processo interno e inerente a um determinado contexto urbano, este seria, obviamente, objeto de análise do urbano propriamente dito. Porém o autor justifica o uso do prefixo intra, tendo em vista que o termo urbano vinculou-se, no campo técnico-conceitual, predominantemente à escala macro, e seria importante buscar uma terminologia correspondente à percepção de determinadas dinâmicas socioespaciais locais.

As considerações de Villaça (1998) são aplicáveis aos processos metropolitanos, de natureza regional, uma vez que os processos intrametropolitanos aqui discutidos têm o propósito de identificar e analisar as dinâmicas locais articuladas e impactadas por processos regionais.

O trabalho de Villaça (1998) discute o intrametropolitano com base em aspectos tais como a mobilidade intraurbana associada às localizações privilegiadas em um determinado centro urbano, cuja apropriação, por classes mais favorecidas, seria geradora de processos de segregação socioespacial.

Entre os estudos pesquisados que abordam especificamente o vocábulo intrametropolitano, foi possível verificar que, em sua maior parte, o termo é utilizado na mesma linha conceitual proposta por Villaça (1998).

\section{Notas sobre a dinâmica do espaço intrametropolitano a partir da fragilidade dos subcentros locais, da forte polarização de Belo Horizonte e da noção de região metropolitana ampliada}

Uma característica fundamental da $\mathrm{RMBH}$ hoje, ressaltada nos estudos do Plano Diretor de Desenvolvimento Integrado da RMBH (PDDI), é a forte polarização da centralidade de primeiro nível, Belo Horizonte, em relação aos demais centros e 
subcentros intrametropolitanos (UFMG; UEMG; PUC MINAS, 2010). Esse estudo ressalta também que a base produtiva da região pode ser considerada ultrapassada, vinculada predominantemente a processos minerometalúrgicos. A obsolescência dessa cadeia produtiva estaria ligada principalmente à natureza predominantemente extrativista dos processos minerários que, mesmo quando associada à implantação de unidades produtivas do setor metalúrgico, geraria contrapartidas socioambientais pequenas se considerados os diversos impactos ocorridos ao longo do processo.

Outra questão ressaltada refere-se à situação de fragilidade de grande parte dos centros locais intrametropolitanos, principalmente em termos de complementaridade e diversidade de usos, o que reforça a polaridade do núcleo principal, Belo Horizonte.

Dentre as diretrizes constantes no PDDI é aqui destacada a importância da ampliação qualitativa do setor de serviços e de produção tecnológica, de forma associada ao fortalecimento dos centros e subcentros intrametropolitanos (UFMG; UEMG; PUC MINAS, 2010).

Monte-Mór (2011) ressalta a importância da adoção de estratégias de desenvolvimento que priorizem o fortalecimento desses subcentros e cita o exemplo recente da crise urbana vivenciada em Detroit, EUA, cuja base econômica se concentrou em uma única atividade, a produção automobilística, que se desenvolveu de forma polarizada no núcleo principal. Nesse contexto, a crise na indústria automobilística local impactou seriamente o espaço urbano de sua região.

O autor traz, como contraponto, o exemplo da Região Metropolitana de São Paulo e demonstra como a adoção de estratégias de desenvolvimento mais equilibradas, priorizando outros centros além da centralidade principal e uma complementaridade entre produção industrial, comércio e serviços foi capaz de consolidar a principal região metropolitana do País.

$\mathrm{Na} \mathrm{RMBH}$ começa a ser identificado um processo que Marques (2011) denomina "região metropolitana ampliada", também discutido por Monte-Mór (2011). A RMBH teria, progressivamente, uma comunicação em termos de rede urbana com a Região Centro-Oeste de Minas, principalmente com os municípios de Itaúna (componente do colar metropolitano), Divinópolis, Nova Serrana, Carmo do Cajuru e com a região do Consórcio para o Desenvolvimento do Alto Paraopeba (Codap), formada pelos municípios de Belo Vale, Congonhas, Conselheiro Lafaiete, Entre Rios de Minas, Jeceaba, Ouro Branco e São Brás do Suaçuí.

Sobre a configuração socioeconômica desses centros, Monte-Mór (2011) ressalta que os municípios do Codap, apesar do alto volume de investimentos privados e públicos em curso na região, repetem uma característica considerada problemática na $\mathrm{RMBH}$, que é o foco em grandes empreendimentos do setor minerometalúrgico, uma base produtiva considerada ultrapassada. $\mathrm{O}$ autor ressalta, por outro lado, que as dinâmicas socioespaciais da Região Centro-Oeste têm uma base econômica mais diversificada, calcada em empreendimentos de menor porte do setor de vestuários, calçados e mobiliários, associados aos serviços públicos e privados dos setores de saúde e educação. Essa base 
econômica seria capaz, de acordo com Monte-Mór (2011), de gerar uma maior complementaridade funcional entre a produção industrial e os setores vinculados ao comércio e aos serviços, e essa experiência poderia, de algum modo, ser trazida com o objetivo de fortalecer os centros intrametropolitanos da RMBH.

As ações para o fortalecimento de centralidades intrametropolitanas e locais na RMBH têm seu foco na consideração de aspectos simbólicos, culturais e econômicos dos centros existentes (MINAS GERAIS, 2009). As políticas públicas adotadas recentemente pela Secretaria Estadual de Desenvolvimento Regional e Política Urbana de Minas Gerais (SEDRU) buscam, para os subcentros da RMBH, incentivar a implantação de centros tecnológicos e de serviços, privilegiando a diversidade e a complementaridade funcional (MINAS GERAIS, 2009).

A SEDRU tem elaborado, desde o ano de 2006, diversos projetos de requalificação urbana e regularização fundiária que buscam priorizar a criação de espaços livres de uso público de forma articulada a centros produtivos e áreas de uso predominantemente residencial (MINAS GERAIS, 2009).

\section{Um estudo de caso: o Município de Betim, a predominância do uso industrial, a baixa complementaridade funcional e a fragilidade dos centros locais}

Com o objetivo de ampliar as discussões deste trabalho, optou-se pela adoção de um estudo de caso que contém os elementos fundamentais concernentes ao tema aqui discutido. Diversos lugares situados na RMBH se enquadrariam nessa discussão, entre os quais podem ser citados os bairros localizados no entorno da Cidade Administrativa do Estado de Minas Gerais (CAMG), principalmente o Morro Alto, pertencente ao Município de Vespasiano, no Vetor Norte da RMBH. Essas áreas, significativamente impactadas pela implantação da CAMG, um equipamento institucional de abrangência metropolitana, têm uma série de dinâmicas socioespaciais locais que necessitam de um tratamento específico, de modo a não se incorrer, simplesmente, no processo de substituição de ocupações e usos. Outro processo passível de discussão seria o Plano de Requalificação de Áreas Urbanas Centrais da RMBH, elaborado pela SEDRU em 2010, no qual centralidades intrametropolitanas situadas nos vetores metropolitanos Norte e Leste (Confins, Lagoa Santa, Ribeirão das Neves, Sabará e Santa Luzia) foram destacadas com o objetivo de se implantarem diretrizes para o fortalecimento de centralidades locais anteriormente propostas pelo governo estadual.

Porém se optou pela discussão de outra dinâmica, localizada no Município de Betim, Vetor Oeste da RMBH. As justificativas para a escolha de um processo localizado no Vetor Oeste se deveram, primeiramente, ao fato de essa região, responsável por abrigar o principal vetor de uso industrial da RMBH, não estar no centro das discussões recentes sobre a produção do espaço metropolitano, que tem priorizado abordagens sobre o Vetor Sul e o Vetor Norte. Apesar disso, o Vetor Oeste da RMBH, associado ao Município de Belo Horizonte, é a porção metropolitana que mais 
receberá investimentos nos próximos dez anos (UFMG, UEMG, PUC MINAS, 2011). O Município de Betim, especificamente, seria o segundo na escala de investimentos na $\mathrm{RMBH}$, atrás apenas da capital (UFMG, UEMG, PUC MINAS, 2011). Essa questão reafirma a importância do Vetor Oeste e, mais especificamente, do Município de Betim no contexto da RMBH.

Outra questão, destacada por Monte-Mór (2011), refere-se ao fato de o Município de Betim, apesar de ter relevância em termos da sua produção industrial, mostrar-se bastante frágil em relação aos usos comerciais e de serviços, associados a uma fragilidade em termos da presença de equipamentos urbanos e comunitários nos bairros de uso predominantemente residencial. Essas questões geram uma estrutura urbana em que são identificados diversos distritos industriais, de diferentes portes, circundados por áreas de uso predominantemente residencial carentes de equipamentos urbanos, comunitários, estabelecimentos comerciais e de serviços. Foi então destacado um caso específico, que é a articulação entre o Distrito Industrial Bandeirinhas, localizado na porção centro-sul do Município de Betim, e
Figura 1 - Área remanescente da Fazenda Roseira que havia sido proposta para tombamento. Fonte: Google Maps

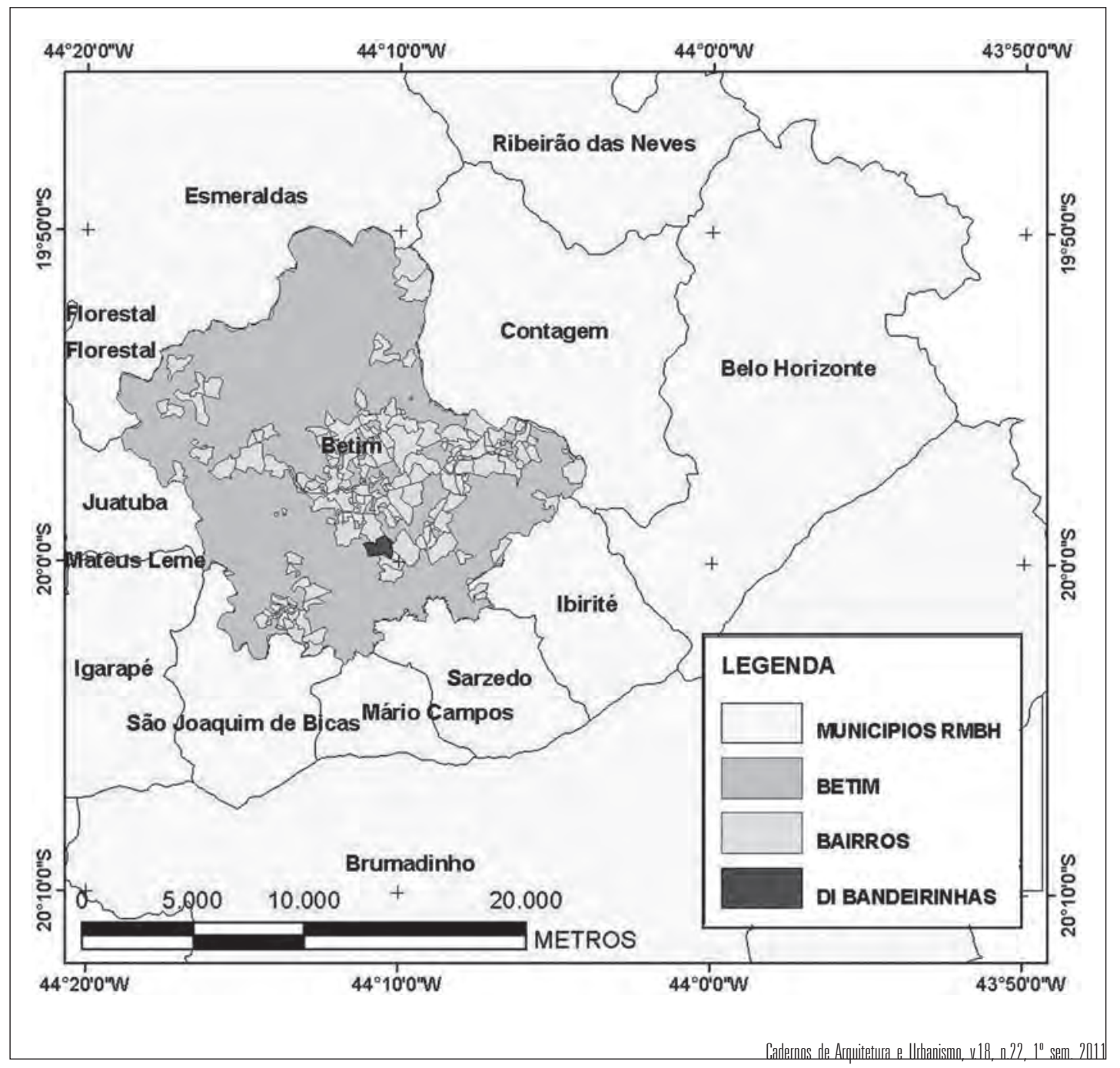


seu entorno imediato, mais especificamente os bairros Chácaras Arapuã e Jardim Primavera. No caso destacado, é possível identificar a síntese dessa estrutura urbana municipal (marcada pela presença do uso industrial, dos usos residenciais do entorno e pela carência de equipamentos urbanos e comunitários, bem como de estabelecimentos comerciais e de serviço). Além disso, esse processo se enquadra nas reflexões sobre o intrametropolitano aqui propostas, tendo em vista a natureza regional dos processos industriais existentes associados ao caráter local dos bairros de uso predominantemente residencial situados no entorno. Além disso, o Distrito Industrial Bandeirinhas foi destacado pela Prefeitura Municipal de Betim como um projeto-piloto que tem, entre seus objetivos, o fortalecimento de usos públicos e institucionais associados à expansão industrial.

O Distrito Industrial Bandeirinhas localiza-se em uma gleba denominada Fazenda Bandeirinhas de Cima, uma área de 120,96 hectares pertencente ao Município de Betim. Desde o início da década de 1990, a área tem sido objeto de diferentes projetos, de um modo geral, de natureza industrial, que culminaram na regularização, em 2008, de 12 terrenos industriais implantados em uma área de 275.285,69 m² no interior da antiga fazenda.

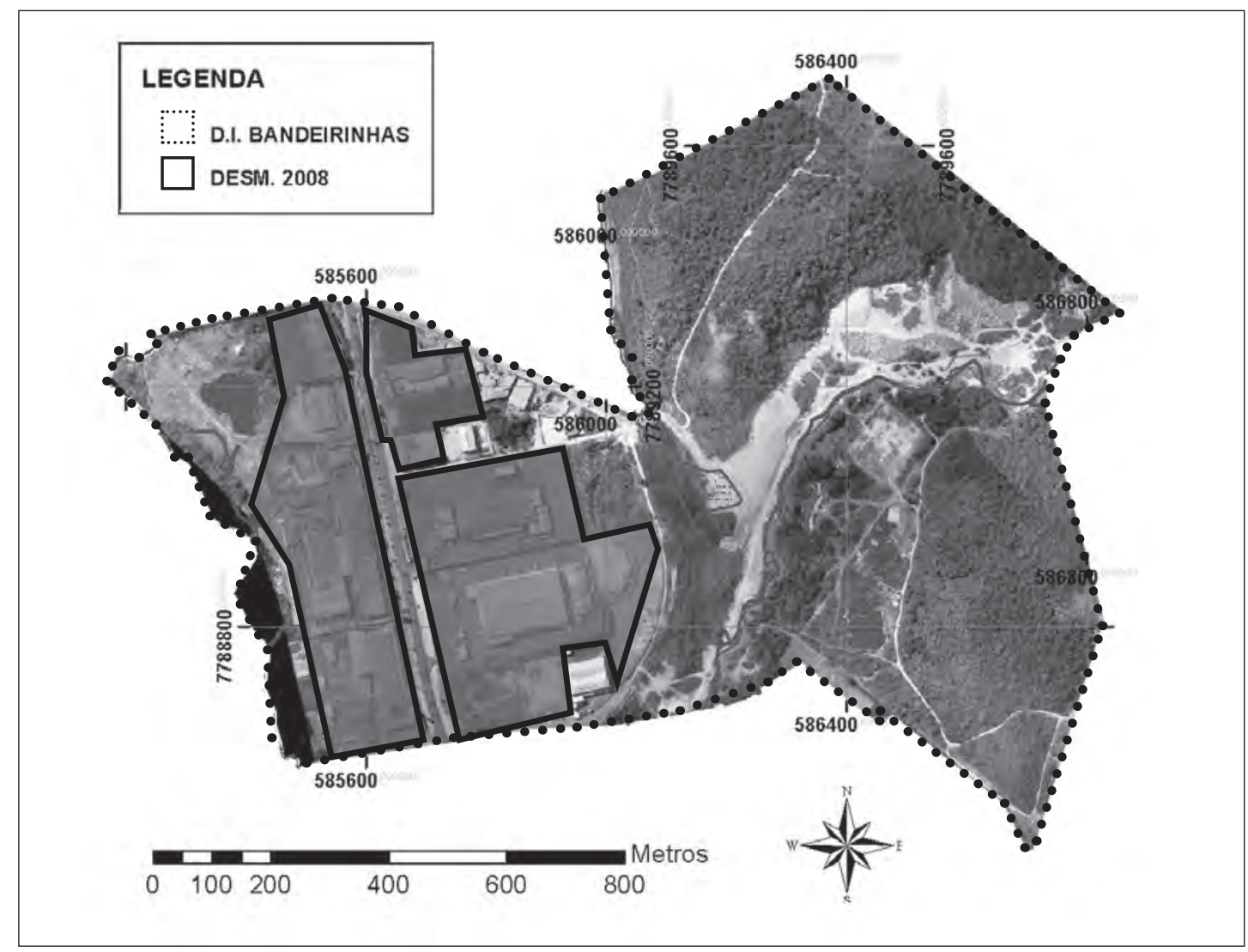

As constantes paralisações no projeto ao longo dos anos acarretaram em dificuldades para a implantação do uso industrial no restante da área, tanto em termos ambientais quanto urbanísticos. Após um levantamento do histórico dos processos de
Figura 2 • A Fazenda Bandeirinha de Cima e os lotes industriais desmembrados em 2008. Fonte: Betim, 2011.

Cadernos de Arquitetura e Urbanismo, v.18, n.22, $1^{0}$ sem. 2011 
aprovação anteriormente empreendidos, verificou-se que tais dificuldades não estavam diretamente vinculadas à má qualidade do projeto existente, mas às paralisações diversas, que deram à área o status de empreendimento de difícil aprovação.

Quando a Prefeitura Municipal de Betim resolveu retomar o projeto no ano de 2010, foi buscada a elaboração de um estudo ampliado em que não seria considerado somente o distrito industrial em si, mas buscadas formas diferenciadas de articulação das indústrias com as áreas residenciais vizinhas.

Os estudos urbanos para a revisão do Plano Diretor Municipal reconheciam a carência de equipamentos comunitários e áreas livres de uso público naquela região, e ressaltavam o problema intraurbano dos distritos industriais circundados por áreas predominantemente residenciais carentes de infraestrutura. Além disso, o Executivo ressaltava a necessidade de que a expansão industrial da Fazenda Bandeirinhas de Cima se desse de modo a responder tanto às demandas industriais quanto ao estabelecimento de soluções formais que melhorassem a articulação com os usos residenciais do entorno.

Desse modo, a partir da análise do projeto existente, foi proposta uma pequena reformulação, de modo que as áreas verdes, então cindidas pelo sistema viário proposto, dessem origem a um Parque Urbano de 24,20 hectares, articulando o Distrito Industrial aos bairros Jardim Primavera e Chácaras Arapuã, de uso predominantemente residencial.

Esse simples remanejamento de áreas verdes, sem uma perda significativa no número de lotes industriais propostos, foi capaz de criar um parque urbano para a população dos bairros vizinhos, solucionando um problema referente à carência de áreas livres de uso público no local.
Figura 3 - A Fazenda Bandeirinhas de Cima, os lotes industriais implantados e o parque Ecológico proposto. Fonte: Betim, 2011.

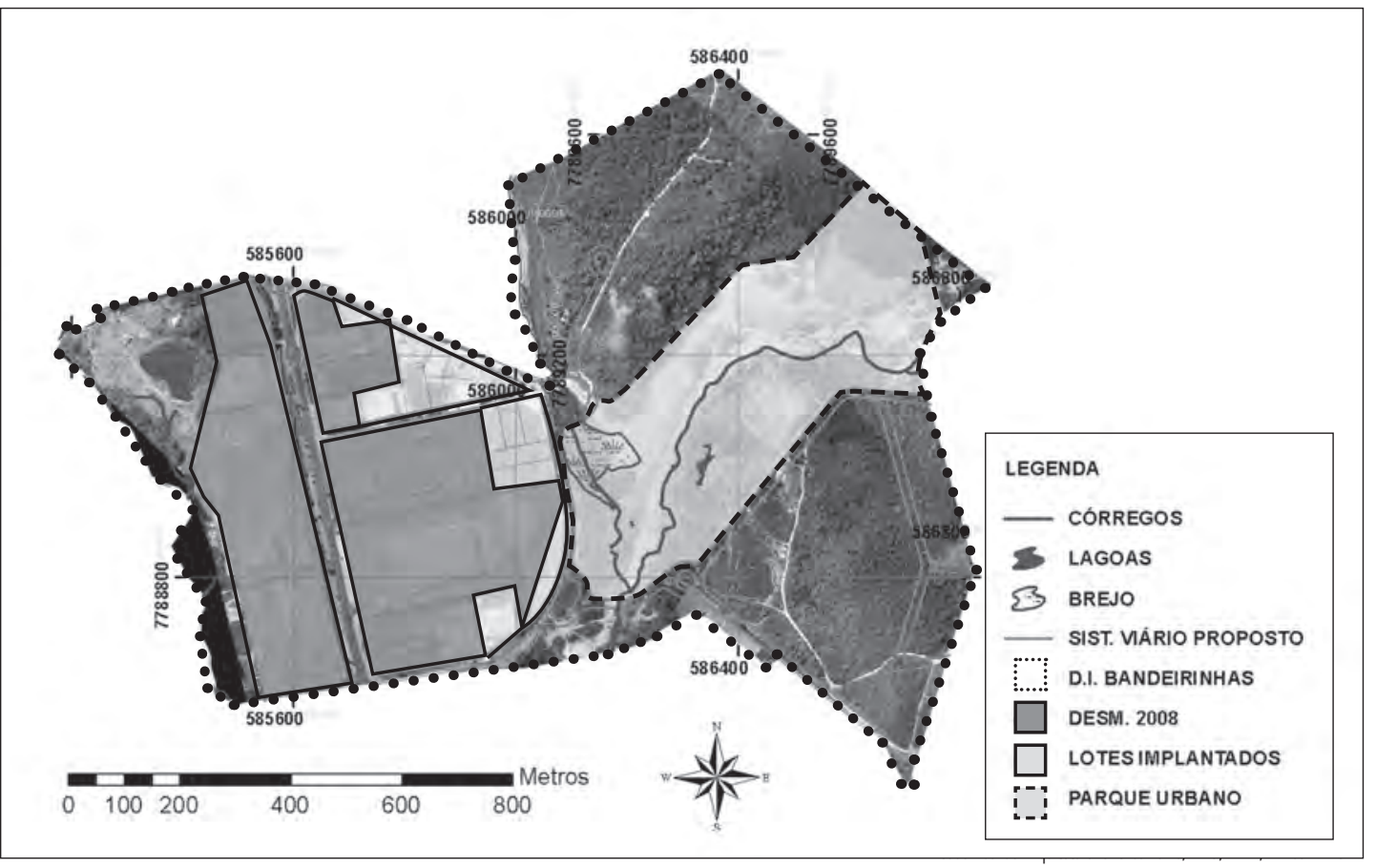


Na busca de estratégias para a realização da proposta, após uma série de discussões, foi feita a opção pelo instrumento Operação Urbana Consorciada (OUC), previsto no Estatuto das Cidades (Lei Federal $n^{\circ}$ 10.257/2001) e no Plano Diretor Municipal (Lei Municipal $\left.n^{\circ} 4.574 / 2007\right)$.

De acordo com a Lei Federal n¹0.257/2001:

Considera-se Operação Urbana Consorciada o conjunto de intervenções e medidas coordenadas pelo Poder Público municipal, com a participação dos proprietários, moradores, usuários permanentes e investidores privados, com o objetivo de alcançar em uma área transformações urbanísticas estruturais, melhorias sociais e a valorização ambiental.

Ainda segundo a referida Lei, uma operação urbana consorciada prevê a modificação de índices e características de parcelamento, uso e ocupação do solo e subsolo, bem como alterações das normas edilícias, sendo considerados os impactos ambientais delas decorrentes.

Com base no disposto acima, foi considerado que a situação da Fazenda Bandeirinha de Cima se enquadraria nas diretrizes referentes a tal instrumento urbanístico.

Tal processo foi então denominado Operação Urbana Consorciada do Córrego Santo Antônio, tendo como limites a poligonal da Fazenda Bandeirinhas de Cima.

O programa básico de ocupação da área seria composto pelas seguintes ocupações e usos:

- implantação do Parque Ecológico do Córrego Santo Antônio, com 24,20 hectares de área, que teria, em seu programa básico, campo de futebol, duas quadras poliesportivas, praça das águas, pista de caminhada, ciclovia, duas quadras de tênis, playground, equipamentos de ginástica, skate parque, portarias, banheiros, bicicletário, administração e uma área institucional destinada à implantação de um espaço denominado "Centro de Apoio ao Desenvolvimento do Ambiente";

- implantação de sistema viário para articulação do parque ao Distrito Industrial e ao Bairro Jardim Primavera;

- implantação de 25 terrenos voltados ao uso industrial, com áreas variadas contendo, em média, $10.000 \mathrm{~m}^{2}$ de área por lote;

- implantação de áreas verdes conectadas ao parque urbano;

- regularização urbanística e ambiental de toda a área.

Foi então previsto, no escopo dessa OUC, que determinadas empresas, receptoras dos lotes industriais, seriam responsáveis, como contrapartida, pela implantação de determinados equipamentos do Parque, a seguir apresentados:

- os lotes industriais 10 e 11 da quadra 5 responsabilizar-se-iam pela implantação do campo de futebol;

- os lotes industriais 8 e 9 da quadra 5 responsabilizar-se-iam pela implantação das duas quadras poliesportivas;

- o lote 7 da quadra 5 responsabilizar-se-ia pela implantação das duas quadras de tênis;

- os lotes 1, 2, 3, 4, 5 e 6 da quadra 6 responsabilizar-se-iam pela implantação da praça das águas; 
- os lotes 1, 2 e 3 da quadra 7 responsabilizar-se-iam pela implantação do skate parque.

A instalação dos demais equipamentos do Parque (pista de caminhada, ciclovia, portarias, bicicletários, administração e equipamentos de ginástica), bem como a sua gestão global, seria de responsabilidade da Prefeitura Municipal de Betim.

Outra questão inserida no âmbito da presente OUC referiu-se à chamada proposição de áreas verdes anexas, que se constituiriam, como o próprio nome já diz, em áreas de preservação anexas ao parque, cuja manutenção ficaria a cargo de outras empresas receptoras de terrenos industriais, da seguinte forma:

- área de preservação 1, com área equivalente a 48.360,51 $\mathrm{m}^{2}$, vinculada à implantação do lote industrial $A$;

- área de preservação 2, com área equivalente a 10.606,02 $\mathrm{m}^{2}$, vinculada à implantação dos lotes industriais 1, 2, 3 e 4 da quadra 4

- área de preservação 3, com área equivalente a 12.623,63 $\mathrm{m}^{2}$, vinculada à implantação dos lotes industriais 5, 6 e 7 da quadra 4;

- área de preservação 4, com área equivalente a 32.475,03 $\mathrm{m}^{2}$, vinculada à implantação dos lotes industriais 1, 2, 3, 4 e 5 da quadra 5;

- área de preservação 5, com área equivalente a 22.974,82 $\mathrm{m}^{2}$, vinculada à implantação do lote industrial 6 da quadra 5 .
Figura $4 \cdot \mathrm{O}$ parque ecológico proposto e as áreas verdes anexas. Fonte: Betim, 2011.

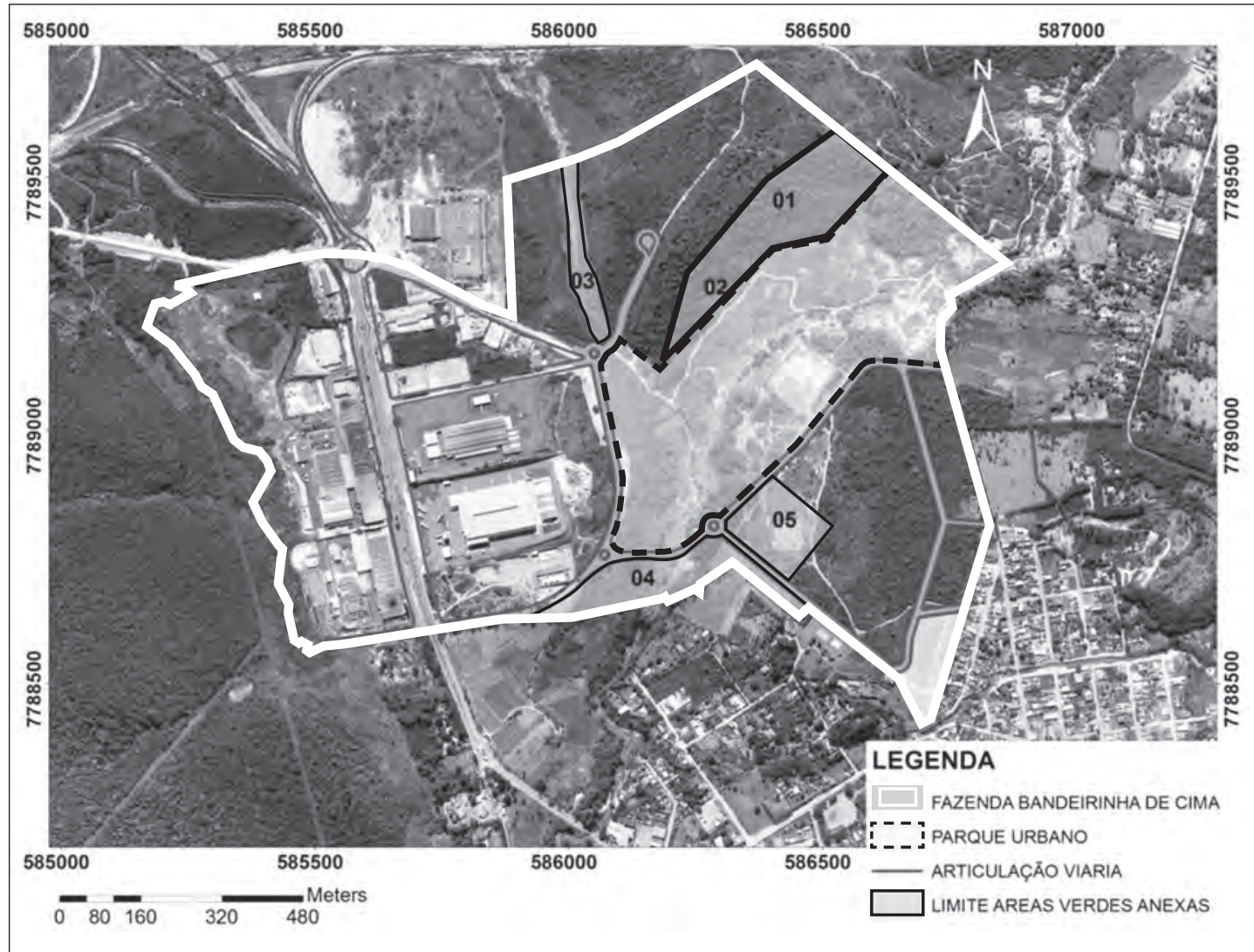

Cadernos de Arquitetura e Urbanismo, v.18, n.22, $1^{0}$ sem. 2011 
plo de parque urbano que tem sua área ampliada conforme as indústrias são instaladas ao longo do tempo. Desse modo, o Parque Ecológico do Córrego Santo Antônio, que teria inicialmente 24,20 hectares, passaria a ter, após a implantação da Operação Urbana, uma área de preservação ambiental total equivalente a 36,90 hectares $(24,20$ hectares iniciais somados às cinco áreas verdes anexas, com 12,70 hectares).

Outra questão fundamental esteve ligada às estratégias de participação adotadas. Foram realizadas reuniões públicas com atores diversos, tais como proprietários de empresas e membros das comunidades locais. Nesse processo, foi possível reconhecer que a área destinada à implantação do parque já vinha sendo informalmente apropriada pela população local como área livre de uso público, por meio de um campo de futebol construído pela própria comunidade e do uso de parte da área para a realização de caminhadas. O projeto urbanístico proposto considerou tais questões, indicando um campo de futebol exatamente no local proposto pela população e considerando as trilhas existentes para a proposição das pistas de caminhada.

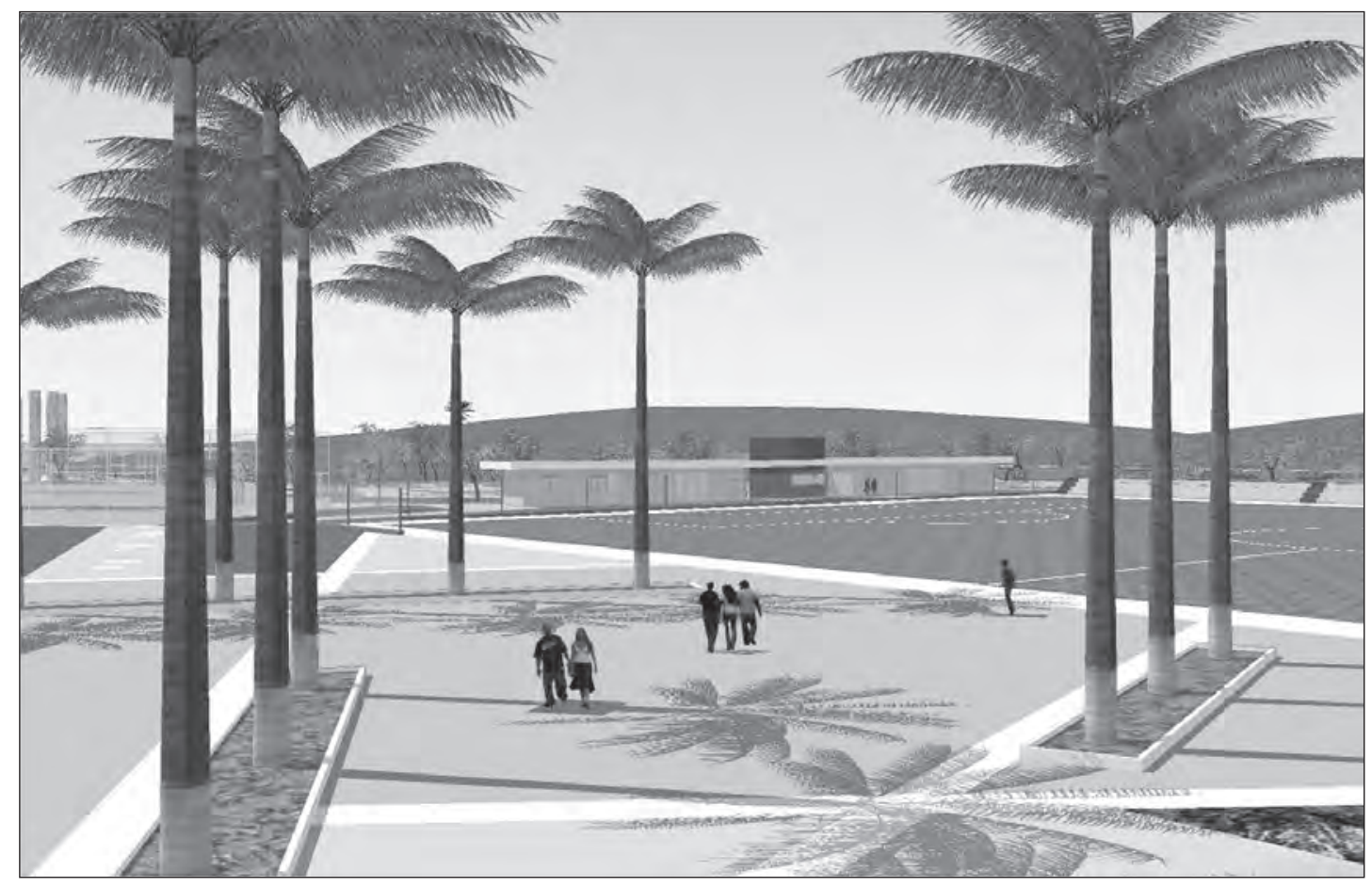

Em janeiro de 2012, a Operação Urbana do Córrego Santo Antônio foi sancionada pelo Executivo Municipal por meio da Lei $n^{\circ}$ $5.254 / 2012$.

Ainda não é possível avaliar os resultados da implantação dessa proposta, porém se entende que, em termos conceituais, ela traz avanços ao promover a articulação entre os planos regionais e municipais existentes, além de construir um arcabouço legal com base no instrumento Operação Urbana Consorciada e elaborar um trabalho de desenho urbano coerente com as questões postas acima.
Figura $\mathbf{5}$ - Vista parcial do projeto do Parque Ecológico do Córrego Santo Antônio, com destaque para a praça localizada em frente ao campo de futebol, proposto na mesma localização do campo de futebol existente no local. Fonte: Betim, 2011.

Cadernos de Arquitetura e Urbanismo, v.18, n.22, $1^{0}$ sem. 2011 


\section{Considerações finais}

As questões discutidas neste trabalho demonstraram a importância de se evitar o distanciamento entre os planos regionais, de abrangência macro, com a fragilidade de processos locais intrametropolitanos.

A operação urbana consorciada discutida no estudo de caso mostra possibilidades de aplicação do instrumento, mostrando potencial para articular diretrizes estabelecidas em escalas e planos diversos.

Ressalta-se também que, tão importante quanto criar novas instâncias, o planejamento e a gestão urbana brasileira clamam por processos que resultem em normas simplificadas, de fácil entendimento e aplicação, associadas à realização dos novos canais de comunicação propostos, sobretudo a partir da Constituição de 1988 e, no campo urbanístico, da Lei n¹0.257/2001.

\section{Referências}

BETIM. Prefeitura Municipal de Betim. Lei $n^{\circ} .5 .254$, de 25 de janeiro de 2012. Institui a Operação Urbana Consorciada do Córrego Santo Antônio e dá outras providências. Betim: Poder Executivo, 2012.

BETIM. Prefeitura Municipal de Betim. Estudos técnicos de urbanismo para a criação da Operação Urbana Consorciada do Córrego Santo Antônio. Betim: Poder Executivo, 2011.

BETIM. Prefeitura Municipal de Betim. Lei $n^{\circ}$. 4.574, de 02 de outubro de 2007. Dispõe sobre a revisão do Plano Diretor do Município de Betim. Betim: Poder Executivo, 2007.

BRASIL. República Federativa do Brasil. Lei ${ }^{\circ}$ 10.257, de 10 de julho de 2001. Regulamenta os artigos 182 e 183 da Constituição Federal, estabelece diretrizes gerais da política urbana e dá outras providências. Brasília: Poder Executivo, 2001.

BRASIL. República Federativa do Brasil. Lei Complementar $\mathrm{n}^{\circ} 20$, de $1^{\circ}$ de julho de 1974 . Dispõe sobre a criação de Estados e Territórios. Brasília: Poder Executivo, 1974.

BRASIL. República Federativa do Brasil. Lei Complementar $\mathrm{n}^{\circ} 14$, de 08 de junho de 1973. Estabelece as regiões metropolitanas de São Paulo, Belo Horizonte, Porto Alegre, Recife, Salvador, Curitiba, Belém e Fortaleza. Brasília: Poder Executivo, 1973.

BRASIL. República Federativa do Brasil. Constituição Federal de 1967. Brasília: Poder Executivo, 1967.

BREMAEKER, F. As finanças municipais em 2007: transparência municipal. Rio de Janeiro: Instituto Brasileiro de Administração Municipal, 2008. (Estudo técnico $N^{\circ} 02$ )

CÂMARA FEDERAL. Assembleia Legislativa da República Federativa do Brasil. Projeto de Lei $n^{\circ} 3460 / 2004$. Cria o Estatuo da Metrópole. Disponível em: <http://www.camara.gov.br/proposicoesWeb/fichadetramitacao? idProposicao $=251503>$. Acesso em: 16 jan. 2012.

CATALÃO, I. (2001). Transição pós-metropolitana e dispersão urbana em Brasília: formas, processos e escalas. In: SIMPURB, 
12, 2011, Belo Horizonte, Anais. Belo Horizonte: Universidade Federal de Minas Gerais, 2011, p. 01-20.

COSTA, G. M.; COSTA, H. S. M. Novas e velhas diferenças: desafios à gestão metropolitana do Vale do Aço. Cadernos de Geografia, Belo Horizonte, v. 12, n. 18, P. 58-73, 2002.

HARVEY, D. The limits to capital. Londres: Verso, 2006.

LEFEBVRE, Henri. A revolução urbana. Belo Horizonte: Editora UFMG, 1999.

MARES GUIA, V. R. A gestão na Região Metropolitana de Belo Horizonte: avanços e limites. In: FERNANDES, E. (org.). Direito urbanístico e política urbana no Brasil. Belo Horizonte: Del Rey, 2001, p. 407-426.

MARQUES, Y. L. Nas sendas do planejamento participativo. Belo Horizonte, 2011. Texto não publicado.

MINAS GERAIS. Governo do Estado de Minas Gerais. Áreas urbanas centrais RMBH. Belo Horizonte: Secretaria Estadual de Desenvolvimento Regional e Política Urbana, 2009.

MONTE-MÓR, R. L. M. Considerações sobre o Plano Diretor de Desenvolvimento Integrado da RMBH. 2011. Palestra proferida no Centro Universitário Metodista Izabela Hendrix, por ocasião do Fórum i-Mobilidade, Belo Horizonte, 2011.

MONTE-MÓR, R. L. M. Urbanização extensiva e lógicas de povoamento: um olhar ambiental. In: SANTOS, M. et al. (orgs.). Território, globalização e fragmentação. São Paulo: Hucitec/ Anpur, 1994, p. 169-181.

REOLON, C. A. \& SOUZA, E. B. C. Questões conceituais: das unidades regionais à Região Metropolitana de Cascavel. In: Revista Geosul, Florianópolis, v. 21, n. 42, p. 113-135, 2006.

ROLNIK, R. Democracia no fio da navalha. Revista Brasileira de Estudos Urbanos e Regionais. São Carlos, v. 11, n. 2, p. 31-50, 2009.

UFMG; UEMG; PUC MINAS. Plano Diretor de Desenvolvimento Integrado da RMBH. 2010. Disponível em: <http://www. agenciarmbh.mg.gov.br/pddirmbhmenu.html>. Acesso em: 10 nov. 2011.

VILLAÇA, Flávio. Espaço intra-urbano no Brasil. São Paulo: Studio Nobel/FAPESP, 1998.

\section{Endereço para correspondência}

Leandro de Aguiar e Souza

Rua Niquelina, 1371, apto. 301

Bairro Santa Efigênia

30270-050 - Belo Horizonte-MG

E-mail: leandrodeaguiar@yahoo.com.br 